\title{
CDISC SDTM Anatomical Location Terminology
}

National Cancer Institute

\section{Source}

National Cancer Institute. CDISC SDTM Anatomical Location Terminology. NCI

Thesaurus. Code C74456.

Terminology codelist used with Anatomical Locations within the Clinical Data Interchange Standards Consortium Study Data Tabulation Model. 